Geopolítica(s) Revista de estudios sobre espacio y poder ISSN: 2172-3958

https://dx.doi.org/10.5209/geop.68749

\title{
La palma de aceite en Tumaco (Colombia) como cuestión geopolítica
}

\author{
Juan David Otálora Sechague ${ }^{1}$ \\ Recibido: 10 de abril de 2020 / Aceptado: 2 de junio de 2021
}

Resumen. El artículo se propone considerar la amenaza de los grupos armados ilegales y los cultivos de uso ilícito como una estrategia de algunas instituciones del Estado colombiano para enmascarar otras rivalidades a propósito del territorio, su uso y explotación en Tumaco. En otras palabras, la producción y distribución de las drogas ha tenido un rol determinista en las explicaciones sobre las rivalidades en ese municipio, eclipsando otros fenómenos que tienen la misma relevancia para sus pobladores como la presencia de las empresas de aceite de palma. Basado en la geopolítica crítica y en un trabajo de terreno realizado en 2018, el texto presenta una serie de argumentos que relacionan los monocultivos de palma de aceite con el desplazamiento y la presencia de grupos armados. La imbricación entre elementos legales e ilegales dan cuenta de tensiones por la apropiación del territorio, en cuyo epicentro se encuentran las representaciones de las comunidades afrodescendientes e indígenas del territorio.

Palabras clave: Tumaco; aceite de palma; afrodescendientes; narcotráfico; tensiones territoriales.

\section{[en] Oil Palm in Tumaco, Colombia, as a Geopolitical Issue}

\begin{abstract}
The article proposes to consider the threat of illegal armed groups and crops for illicit use as a strategy of some Colombian State institutions to hide other rivalries regarding the territory, its use and its exploitation in Tumaco. In other words, the production and distribution of drugs has had a deterministic role in the explanations of rivalries in that municipality, overshadowing other phenomena that have the same relevance for its habitants, such as the presence of palm oil companies. Based on critical geopolitics and the fieldwork carried out in 2018, the text presents a series of arguments that link oil palm monocultures with dis-placement and the presence of armed groups. The overlap between legal and illegal elements reveals tensions on territory appropriation, in whose epicenter are the representatives of the Afro-descendant and local indigenous communities.
\end{abstract}

Keywords: Tumaco; Palm oil; Afro-descendants; drug trafficking; territorial tensions.

\section{[pt] O dendê em Tumaco (Colômbia) como uma questão geopolítica}

Resumo. O artigo propõe considerar a ameaça de grupos armados ilegais e plantações para uso ilícito como estratégia de algumas instituições do Estado colombiano para mascarar outras rivalidades em relação ao território, seu uso e exploração em Tumaco. Ou seja, a produção e distribuição de drogas tem desempenhado um papel central nas explicações das rivalidades naquele município, ofuscando outros fenômenos que têm a mesma relevância para seus habitantes, como a presença de empresas de dendê. A partir da geopolítica crítica e de um trabalho de campo realizado em 2018, o texto apresenta

1 Universidad El Bosque, Bogotá (Colombia).

Email: jotaloras@unbosque.edu.co

https://orcid.org/0000-0002-0053-3478 
uma série de argumentos que vinculam as monoculturas de dendê ao deslocamento e à presença de grupos armados. A imbricação entre elementos legais e ilegais revela tensões pela apropriação do território, em cujo epicentro estão as representações das comunidades afrodescendentes e indígenas do território.

Palavras-chave: Tumaco; óleo de palma; Afrodescendentes; narcotráfico; tensões territoriais.

Sumario. Introducción. 1. Tumaco como escenario de disputa territorial. 1.1. Multiplicidad de actores, diversidad de intereses. 1.2. La geografía de la periferia: el puerto lejano. 2. La palma de aceite en Tumaco: una geografía del poder. 3. Ocupaciones y desplazamientos. Consideraciones finales. Agradecimientos. Referencias.

Cómo citar: Otálora Sechague, J. D. (2021). La palma de aceite en Tumaco (Colombia) como cuestión geopolítica. Geopolítica(s). Revista de estudios sobre espacio y poder, 12(2), 231-253. https://dx.doi.org/10.5209/geop.68749

\section{Introducción}

En la que es probablemente su obra más reveladora, La géographie, ça sert d'abord à faire la guerre (1976) (traducida al español como "Geografía: un arma para la guerra"), el profesor francés Yves Lacoste planteó que la geografía, en tanto saber estratégico, cumple una función para el control y organización de las sociedades que pueblan un territorio. Sin embargo, quizás, el mayor aporte de la obra de Lacoste es la reflexión en torno al carácter "enmascarador" de la geografía. Por tanto, "la proeza ha consistido en hacer pasar un saber estratégico militar y político por un discurso pedagógico o científico totalmente inofensivo" (Lacoste, 1976, p.9). A partir de los postulados de la que sería llamada geografía crítica (o radical) desarrollada desde la década de 1970, se produjo un cambio notable en la comprensión de la díada espacio y poder con el propósito de "desenmascarar" el discurso geográfico-ideológico de las élites políticas, económicas y militares. En consecuencia, diversos actores, más allá de los tradicionalmente asociados al poder o su ejercicio, contaron con herramientas para interpretar los conflictos por y a propósito del territorio.

Inspirado en este razonamiento, el presente trabajo busca poner de manifiesto algunos conflictos territoriales "enmascarados" en Tumaco, zona localizada en el extremo suroccidental de Colombia, en las costas del Océano Pacífico. Esta ciudadpuerto, frontera con el Ecuador, es probablemente el territorio que mejor sintetiza las tensiones desatadas luego del acuerdo de paz firmado por el gobierno colombiano y las Fuerzas Armadas Revolucionarias de Colombia (FARC) ${ }^{2}$. En efecto, allí se concentra la acción de al menos nueve grupos armados con distintas orientaciones ideológicas, entre los que se encuentran las autodenominadas Guerrillas Unidas del

2 El Acuerdo final para la terminación del conflicto y la construcción de una paz estable y duradera (Gobierno de Colombia, 2018) es el resultado de un arduo proceso iniciado en 2012 y cuyo epílogo se dio con la firma del teatro Colón, el 24 de noviembre de 2016, en el que el gobierno del entonces presidente Juan Manuel Santos, realizó algunos cambios al documento final, luego de la derrota en las urnas del plebiscito que buscaba el respaldo de la población al proceso de paz. El Acuerdo contiene los principales puntos de negociación entre el Estado y la guerrilla de las FARC, entre los que se destacan: tierras y Reforma Rural Integral (RRI); apertura de la participación política de los sectores de oposición; fin del conflicto y dejación de las armas; solución al problema de las drogas y derechos de las víctimas. Este documento que desde su difusión no ha estado exento de polémicas, constituye la piedra angular del proceso de posconflicto y continúa siendo uno de los temas de discusión en el debate político colombiano. 
Pacífico (disidencias de la columna Daniel Aldana de las FARC), grupos neo-paramilitares y auténticos ejércitos narcotraficantes patrocinados por el Cartel de Sinaloa. Además, de acuerdo con un informe de las Naciones Unidas, Tumaco es el principal municipio productor de hoja de coca a nivel nacional con más de 23.000 hectáreas (de las 62.446 de la región Pacífica) (UNODC, 2019, p.96). Empero, estas no son las únicas problemáticas presentes en el territorio por lo que el estudio buscará desentrañar aquellas rivalidades que, por distintas razones, no son debatidas en la misma dimensión que el narcotráfico como es el caso de los monocultivos de palma de aceite.

Dicho esto, San Andrés de Tumaco posee una extensión territorial de $3.778 \mathrm{~km}^{2}$ y una población estimada de 212.692 personas, de las cuales el $89 \%$ se reconoce como raizal, palenquero, negro, mulato, afrocolombiano o afrodescendiente; en tanto que el 5\% pertenece a un grupo indígena (fundamentalmente de la etnia Awá) y el restante $6 \%$ no tiene una filiación étnica particular (DANE, 2018). Esta distribución de la población es fundamental para comprender las rivalidades por el acceso y uso de la tierra. En efecto, en Tumaco coexisten dos modelos de apropiación del territorio: uno de uso privado dedicado principalmente a la producción de monocultivos y otro de título colectivo perteneciente a los Consejos Comunitarios de los grupos afrodescendientes y resguardos indígenas que, de acuerdo con las leyes vigentes en la materia, tienen el derecho a desarrollar sus prácticas tradicionales de producción. No obstante, como se verá a lo largo de la investigación, la imbricación, combinación y/o contradicción de estos modelos ha desencadenado rivalidades por el acceso e interpretación del territorio, elemento central en el análisis geopolítico.

Esto quiere decir que Tumaco en tanto escenario de confrontaciones hace parte de los análisis locales, regionales, nacionales e incluso internacionales a causa del narcotráfico. Aunque el profesor Philippe Subra (2016) sostiene que raramente en los escenarios de geopolítica local hay confrontaciones que incluyan asesinatos, Tumaco es sin duda la excepción a esa regla. Este hecho podría hacer creer entonces que la situación está relacionada con la "seguridad nacional" y que, por tanto, el Estado debe intervenir para solucionar las problemáticas; pero al analizar las circunstancias más de cerca surge una gran diversidad de actores que dejan entrever otros problemas y en algunos casos más agudos. En esta lucha de representaciones también está en juego el nivel de análisis de los problemas ${ }^{3}$. Mientras el Estado pretende centrar en el narcotráfico la causa de las confrontaciones y el peligro global que ello representa, las comunidades afrodescendientes e indígenas buscan, de diversas maneras, llamar la atención sobre problemas locales como la distribución del territorio, la minería legal e ilegal y el acaparamiento de grandes extensiones de tierra para la siembra de monocultivos. Huelga decir que, los resultados del presente trabajo de investigación se basaron en los testimonios recogidos en un trabajo de campo que contaron con la participación de diversos líderes comunitarios de Tumaco, cuyos

\footnotetext{
La representación es uno de los conceptos centrales en el análisis geopolítico. Para efectos del presente documento se entenderá por representación la imagen que un grupo social genera sobre un territorio específico cuyo propósito es crear una funcionalidad simbólica. Por esa razón, también pueden ser construidas de manera consciente al servicio de una estrategia geopolítica de comunicación. En consecuencia, "el éxito de una representación construida y voluntaria es completo cuando es percibido por la opinión pública no como una representación sino como una verdad, una evidencia, es decir, cuando se convierte en una representación inconsciente" (Subra, 2016, p.31). Este elemento será crucial para comprender cómo el narcotráfico se ha erigido como uno de los factores explicativos deterministas en el conflicto social colombiano, dejando de lado (o minimizando su importancia) a otras rivalidades por la tierra.
} 
nombres son omitidos por razones de seguridad. El objetivo es contrastar estas versiones con una serie de documentos producidos desde el gobierno colombiano y sus múltiples agencias. Desde esta perspectiva, sin desconocer las consecuencias devastadoras del narcotráfico, se observa un subregistro por parte del gobierno de las problemáticas asociadas al cultivo de palma y otros problemas por el uso y acceso al territorio.

Tomando en cuenta los elementos anteriormente expuestos, la hipótesis de trabajo girará en torno a considerar la amenaza de los grupos armados ilegales y los cultivos de uso ilícito - y por extensión de toda la cadena del narcotráfico- como una estrategia de algunas instituciones del Estado colombiano para enmascarar otros desafíos y problemáticas alrededor del territorio, su uso y explotación en Tumaco. No se trata, sin embargo, de negar la relevancia del narcotráfico como fenómeno social, pero sí de otorgar importancia a confrontaciones que, a nuestro juicio, reciben menos atención - aunque es claro que importantes científicos sociales se han esforzado por poner de manifiesto fenómenos territoriales que superan la interpretación del tráfico de narcóticos, entre tantos, Escobar (2014, 2016), Houghton (2008), Oslender (2004, 2008), De Friedemann y Arocha (1986), Arocha (2004) y Hoffmann (2007)—. Será como en el escenario de un teatro: el reflector estará puesto en otras problemáticas sin negar la existencia del tráfico de estupefacientes. En todo caso, son fenómenos que tienen una estrecha relación y que comparten una característica esencial: las rivalidades por la apropiación del territorio.

\section{Tumaco como escenario de disputa territorial}

La ciudad-puerto de Tumaco es posiblemente uno de los territorios en los que se pondrá a prueba con mayor riesgo el éxito del posconflicto. Las estrategias para el remplazo de cultivos de uso ilícito, así como los mecanismos que asegurarán la Reforma Rural Integral (RRI), son elementos esenciales para solventar la situación en un municipio cuya tasa de necesidades básicas insatisfechas es de $48,7 \%$ (casco urbano) y 59,3\% (zona rural), en tanto que el porcentaje de personas en situación de miseria es de 16,7\% (casco urbano) y 25,9\% (zona rural) (Ortiz, 2018). A esta circunstancia se suma que el $69 \%$ del total de los ingresos generados en el municipio estén concentrados en el 10\% más rico de su población (Palma, 2014, p.6). Sin el propósito de caer en determinismos geográficos, una de las posibles causas de esa circunstancia son las condiciones del espacio, que alimentaron la narrativa de "periferia" o "zona marginal". De hecho, la mayor parte de Tumaco es selva tropical, atravesada por una intrincada hidrografía. Pueden contarse al menos veinte ríos, dentro de los que se destacan el Mira y el Patía que desembocan en el Océano Pacífico. Esta geografía variopinta ha hecho que el acceso desde la cordillera sea complicado, situación que marcó desde la independencia una desconexión con el centro del país y expandió la representación del aislamiento y abandono estatal.

En efecto, la construcción del Pacífico colombiano se dio de manera compleja y desigual. Las migraciones de esclavizados de plantaciones de Popayán y sus alrededores se fueron consolidando a lo largo del siglo XIX en "espacios costeros 'libres' poco o nada integrados al sistema esclavista y en general a la sociedad nacional" (Hoffmann, 2007, p.56). Autores como De Friedemann y Arocha (1986), sostienen que la presencia de familias negras en el Pacífico se desarrolló de manera progresiva 
y en escenarios de relativa calma. De hecho, hasta entrada la década de 1980, se hablaba de este litoral como un "refugio o remanso de paz". Este escenario, no obstante, se alteró por la "integración económica" con el centro del país y, por supuesto, con la llegada de grupos armados ilegales. Así, la población local comenzó a ser desplazada de sus territorios al menos de tres formas distintas: mediante el "consenso", a través de la violencia y por medio de la explotación (Reyes, 2017). Además, una de las consecuencias de estos procesos de exclusión ha sido el hecho de "invisibilizar" las luchas de las comunidades negras e indígenas y de su apropiación territorial ${ }^{4}$.

El concepto de "territorio baldío" (tierra sin títulos de propiedad, pero no deshabitadas) es una buena ilustración del proceso anteriormente descrito. Según la ley 110 de 1912 y otras, los territorios de este tipo son propiedad del Estado y son susceptibles de adquirirse por medio de un título legal. Sin embargo, de acuerdo con uno de los líderes de los Consejos Comunitarios de Tumaco, el concepto de "baldío" hace referencia a "territorios abandonados, sin amos, ni límites establecidos. Pero las comunidades negras han ocupado estos espacios durante siglos, por lo que no

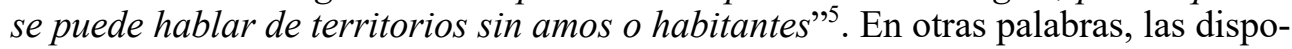
siciones legales anteriores a 1991 negaron la existencia de una comunidad étnicamente diferenciada y promovieron un sistema de títulos de propiedad de la tierra que favorecía a los empresarios extranjeros y de la zona andina del país, elemento central en la historia de las rivalidades por la tierra en este municipio.

De acuerdo con la periodización del profesor Eduardo Restrepo (1999), la construcción de la ciudad de Tumaco se llevó a cabo en cuatro etapas. La primera desde su fundación en 1640 hasta la segunda mitad del siglo XIX se caracterizó por la marginalidad económica en comparación con los municipios vecinos de Barbacoas e Iscaundé (donde había grandes yacimientos de oro). La segunda incluye las dos últimas décadas del siglo XIX y se extiende hasta 1940, luego de que Tumaco se convirtiera en un importante centro económico debido a la explotación de tagua (marfil vegetal), así como la llegada de capitales extranjeros, lo que significó la movilización de comunidades negras en la región en busca de trabajo. El tercer momento estuvo marcado por el crecimiento de la explotación de madera desde 1940 hasta mediados de la década de 1970. Finalmente, la cuarta etapa, desde 1980 hasta la actualidad, se caracteriza por el surgimiento de la agroindustria del aceite de palma y las empresas camaroneras. El elemento transversal de estas circunstancias históricas fue, por un lado, la ausencia de títulos de propiedad para las comunidades afrodescendientes y, por otro, la "producción de un espacio con una marcada tendencia "elitista" y "racista" (Agier, 1995), ya que los industriales blancos obtuvieron ventajas sobre la posesión y explotación de la tierra, causando la marginación y el desplazamiento de las comunidades étnicas.

Cabe agregar que la llegada de las cadenas del narcotráfico a Tumaco es relativamente reciente y está relacionada con las fumigaciones con glifosato en el marco de las operaciones militares del "Plan Colombia" en los departamentos de Putumayo,

4 Uno de los trabajos seminales al respecto de la "invisibilización" de las comunidades negras es el propuesto por la antropóloga colombiana Nina De Friedemann. Puede hacerse particular mención dentro_de su vasta obra a $L a$ saga del negro: presencia africana en Colombia (1993) y Criele criele son del Pacífico negro. Arte, religión y cultura en el litoral del Pacifico (1989).

5 Entrevista realizada con un líder de uno de los Consejos Comunitarios en Tumaco. Nos reservamos el nombre por razones de seguridad. 
Caquetá, Guaviare y Meta a partir de $1999^{6}$. Estas acciones provocaron la migración de los denominados "campesinos cocaleros" sobre la costa Pacífica y la siembra de cultivos de uso ilícito sobre las inmediaciones de los ríos Mira y Mataje. Sólo hasta entrada la década de los 2000 se inició un proceso de crecimiento exponencial de los cultivos de uso ilícito (Escobedo y Palacios, 2009). En este escenario, diversos actores se disputan, a través de diferentes medios, el acceso y posesión de la tierra en la ciudad-puerto.

\subsection{Multiplicidad de actores, diversidad de intereses}

Como se ha mencionado, en Tumaco cohabitan dos grupos étnicamente diferenciados con formas organizativas específicas que tienen una relación directa con el territorio. De una parte, se encuentran las comunidades negras, cuyo acceso y propiedad del territorio está reglamentado por el artículo transitorio 55 de la Constitución Política de 1991 y la ley 70 de 1993. El objetivo de esta ley era establecer los mecanismos para la protección de la identidad cultural y los derechos de esas comunidades, así como la titulación colectiva de los territorios de acuerdo con sus prácticas tradicionales. De hecho, en el artículo cuarto se menciona que el Estado otorgará la propiedad colectiva sobre áreas legalmente definidas y que se conocerán como "tierras de las comunidades negras" (Ley 70 de 1993). Para obtener este beneficio, los grupos tenían que organizarse dentro de Consejos Comunitarios, que son unidades administrativas encargadas de delimitar las áreas asignadas y garantizar la protección del derecho de posesión de la tierra. Actualmente, Tumaco cuenta con dieciséis Consejos Comunitarios en los que 7.720 familias (41.633 personas) viven en un área de 175.570 hectáreas.

No obstante lo anterior, escritoras como Odilie Hoffmann (2007) sostienen que la organización de pueblos afrodescendientes en Consejos Comunitarios fue una "invención sobre medida" que permitió, por una parte, a la élite negra local un campo de expresión y de reconocimiento sociopolítico y, por otra, al gobierno colombiano, promover la creación de un interlocutor válido para el surgimiento de negocios agroindustriales y la llegada de capitales extranjeros. Así las cosas, replicando el modelo indígena, "los consejos comunitarios aparecen como una instancia igualmente ancestral, cuando ni lo uno (el territorio colectivo) ni lo otro (el consejo comunitario) son unánime y sistemáticamente aceptados en el Pacífico" (Hoffmann, 2007, p.42).

Dicho de otro modo, la construcción de estas instancias administrativas se dio en el marco de la apertura económica promovida por la carta política de 1991 — que, de manera simultánea, promovió la protección de los derechos étnicos-. Sin embargo, diversos grupos campesinos, particularmente en el departamento de Nariño se han resistido a acoger como válida la titulación colectiva, al igual que algunos grupos afrodescendientes. Esta aclaración es pertinente pues no se puede hablar de las comunidades negras como un bloque monolítico, pues como cualquier organización

\footnotetext{
6 El "Plan Colombia" es el nombre con el que se conoce la ayuda militar de más de mil millones de dólares prestada por el gobierno de Estados Unidos a Colombia para la lucha contra el narcotráfico. El acuerdo suscrito por los presidentes Bill Clinton y Andrés Pastrana, produjo una reducción significativa de los cultivos de uso ilícito en el país, pero trajo a su vez, notables consecuencias. Entre ellas se encuentran las aspersiones aéreas con glifosato, el repliegue estratégico de las guerrillas en el sur del país y el aumento de las víctimas del conflicto armado en un promedio de 300.000 por cada año de implementación del Plan (Albaladejo y Haugaard, 2016).
} 
política, tiene múltiples instancias, facciones, debates internos y matices que dan cuenta de su complejidad histórica.

Por otra parte, en la zona rural del municipio hay quince reservas indígenas, una de las cuales pertenece al grupo étnico Eperara Siapidara, y los restantes se agrupan en la Unidad de Pueblos Indígenas Awá (UNIPA). Las reservas ocupan 71.881 hectáreas y están ubicadas en áreas sensibles del municipio; verbigracia, la reserva $\mathrm{La}$ Turbia localizada en la frontera con el Ecuador, donde los intereses de los actores armados se unen para la producción de hoja de coca y la exploración ilegal de oro (Sánchez, 2017). De la misma manera, los territorios indígenas se convirtieron en objeto de disputa por parte de los "campesinos colonos" que migraron a Tumaco desde los años 1990. Esta amalgama de intereses ha llevado al desarrollo de rivalidades por la posesión de la tierra.

Luego de la llegada del narcotráfico al sur del país y el consecuente repliegue del bloque occidental de las FARC (frentes $6,8,29,30$ y 60) a causa de los ataques a $\mathrm{La}$ Uribe, Meta, se conformó un nuevo escenario de confrontaciones en el departamento de Nariño (García, 2011). Durante la década de 1990, la guerrilla inició ataques sistemáticos al oleoducto trasandino, secuestró a 42 personas entre ellas alcaldes y parlamentarios locales y extorsionó a los principales empresarios de la palma de aceite. En respuesta a estas acciones, el bloque Libertadores Sur de las Autodefensas Unidas de Colombia (AUC) hizo presencia en Nariño e inició una sangrienta lucha por el control del espacio.

Dos momentos clave reconfiguraron las relaciones de poder y las disputas armadas en Tumaco. De un lado, la presunta desmovilización de las AUC efectuada durante el gobierno de Álvaro Uribe Vélez que, dicho de paso, resultó polémica pues algunas estructuras no entregaron las armas y el proceso resultó insuficiente en términos de reparación y justicia (CNMH, 2015). De hecho, entre 1990 y 2000 grupos paramilitares asesinaron a más de 25.000 personas y se apropiaron militarmente de seis millones de hectáreas, las cuales no fueron devueltas a sus legítimos dueños a causa de la presión de nuevos actores armados que heredaron la estructura criminal como los Rastrojos, las Águilas Negras y la Nueva Generación (García, 2011).

El segundo momento fue el proceso de paz entre el gobierno y las FARC, que culminó con la firma de los acuerdos de La Habana y el plebiscito del 2 de octubre de 2016. Por un estrecho margen, el voto a favor del "No" obtuvo una victoria que se concentró en las cordilleras central y oriental - con excepción de Bogotá y Boyacá, donde el "Sí" triunfó-. Un primer análisis de los resultados daría cuenta de que las poblaciones afectadas por el conflicto tendieron a apoyar el Acuerdo, mientras que las que se opusieron no lo sufrieron de forma directa. Éste sería el caso, por ejemplo, de Tumaco donde las acciones de la guerrilla fueron particularmente intensas y, a pesar de ello, el "Sí" obtuvo una victoria contundente $(71,10 \%$ contra $28,80 \%$ ). Caso similar al de sus municipios vecinos donde se vivieron de cerca las consecuencias de la guerra y el "Sí" triunfó de manera categórica: Roberto Payán (91,51\%), Francisco Pizarro (84,35\%), Magüi $(93,13 \%)$, Barbacoas $(74,82 \%)$ y Mosquera (89,81\%).

No obstante, de acuerdo con la lectura del profesor Yann Basset, esta idea debe ser matizada. En efecto, "los desplazamientos masivos de poblaciones que provocó el conflicto limitan mucho la posibilidad de llegar a esta conclusión" (Basset, 2018, p.247). De acuerdo con esa perspectiva, dos factores influyeron particularmente en los resultados del plebiscito: por una parte, la fuerte abstención $(62,57 \%) \mathrm{y}$, por otra, 
la ausencia de movilización de electores a favor del Acuerdo. Realizando una comparación con las elecciones presidenciales de 2014, Basset concluye que el plebiscito del 2 de octubre fue más bien una derrota del "Sí" — que no pudo movilizar a la Costa Atlántica como lo hizo a favor de la campaña de Juan Manuel Santos- que una victoria del "No", con lo cual, se aleja de la interpretación geográfica de los resultados.

Con todo, a pesar de la desmovilización de los dos grupos ilegales más conocidos e influyentes, en Tumaco la violencia persiste por cuenta de las estructuras heredadas de las guerrillas y el paramilitarismo. Así pues, después del "vacío territorial" que dejaron las FARC, algunos disidentes que no se acogieron al proceso de paz decidieron continuar con la lucha armada. El primer grupo es la Gente del orden, cuyas acciones se concentran en los barrios Viento Libre y Panamá Nueve en el área urbana de Tumaco. De esta organización surgieron las autodenominadas Guerrillas Unidas del Pacífico (GUP), grupo ilegal que actúa también en el perímetro urbano del municipio de Tumaco, así como en el sector Laguna de Chimbuza, Pirí, Nerete y en la zona rural de Llorente, el Charco, Santa Bárbara de Iscaundé, Piñal Salado, Pindales, Bajo Guabal, y en los municipios vecinos de Roberto Payán y Francisco Pizarro ${ }^{7}$.

Así mismo, otra de las estructuras de las GUP que se conformó a partir del Frente Oliver Sinisterra, actúa en las orillas de los ríos Mira y Mataje (en el Consejo Comunitario Alto Mira y Frontera), las veredas de Pusbi, Pusbi Alto, Balsa, Casas Viejas, Puerto Rico, Brisas del Mataje, el Pan, Mina, el Azúcar, el Tandil y El Vallenato, en el área de la frontera con Ecuador. Gracias a su posición estratégica, esta disidencia busca controlar los ríos Mira y Mataje para utilizarlos como canales de transporte y suministro para sus cuadrillas, así como para el paso de cocaína. Finalmente, el otro grupo guerrillero histórico, el Ejército de Liberación Nacional (ELN) está presente en la zona norte de Tumaco a través del Frente Comuneros Sur (compañía Héroes y Mártires de Barbacoas). Aunque el papel de esta guerrilla es nuevo en Tumaco, el fortalecimiento de otras organizaciones ilegales en la zona, hará que la disputa por el control territorial sea bastante compleja.

En efecto, algunos grupos paramilitares (o sus reductos) buscan pelear el control de las rutas del narcotráfico y la explotación de las minas ilegales. El grupo más influyente es el Clan del Golfo, ubicado en las zonas fronterizas con Ecuador en el río Patía y en algunas regiones costeras de Tumaco como Agua Clara, Mascarey, El Aguacate, Iguapí e Imbilí. Existen además pequeñas organizaciones criminales que no sobrepasan los 50 hombres en armas y se encargan del microtráfico y las extorsiones. Cabe mencionar, además, la presencia de otro actor involucrado en el conflicto y es el grupo privado de narcotraficantes mexicanos del cartel de Sinaloa cuyas funciones se concentran en los territorios del Consejo Comunitario de Alto Mira y Frontera, liderados por alias "Chachi".

\subsection{La geografía de la periferia: el puerto lejano}

"Tú comienzas a entender la geografía de la guerra cuando te mueves por esos ríos, donde nadie está presente", explica Christian Visnes, director en Colombia del

Toda la información geográfica relacionada con la situación de la criminalidad, la composición de sus grupos y su naturaleza fue extraída de entrevistas realizadas, así como los informes del Ministerio de la Defensa y de Restrepo (2018). 
Consejo Noruego de Refugiados, una de las asociaciones presentes en el sur del país (Verdad Abierta, 2015). Esta sentencia resume en buena medida la situación en Tumaco que, a pesar de estar conectada a través de una carretera con la capital departamental y de contar con el aeropuerto La Florida (inaugurado en 1940) es uno de los municipios más alejados del país. Esta circunstancia que bien puede explicarse por las condiciones geográficas (naturaleza selvática, climas tropicales e intrincada hidrografía), se debe también al excesivo poder central históricamente ejercido desde Bogotá que impidió el desarrollo del poder regional. A esto se suma la actitud de las élites políticas frente a los habitantes de la región pacífica que no fueron reconocidos como propietarios de territorios sino como ocupantes de "zonas baldías".

El "descubrimiento" de la periferia sólo fue útil para la creación de lucrativos negocios aprovechando la condición de ciudad portuaria. Por ese motivo, un conflicto de representaciones se ha erigido en Tumaco. De un lado, una interpretación andina/central que observa un territorio "vacío" como posible escenario de crecimiento económico y, por otro, una representación local/periférica cuya lucha se basa en el reconocimiento de la tenencia de la tierra y el reconocimiento político de las comunidades que lo habitan. A esto se suma la perspectiva crítica que algunas instituciones como el Consejo Nacional de Paz Afrocolombiano han tenido sobre el proceso de paz, calificando incluso de "preacuerdo" a lo conseguido en La Habana, pues según su perspectiva, no es un verdadero Acuerdo hasta tanto no se consulten a las comunidades étnicas (Caicedo, 2016). Otras voces han propuesto la creación del departamento del Pacífico como la organización territorial que aglutine a las comunidades afrocolombianas como una alternativa que permita el desarrollo y reconocimiento locales. ${ }^{8}$. Por tanto, es común escuchar la referencia de que uno de los principales problemas de Tumaco ha sido "el histórico abandono del Estado".

Esta percepción sigue formando parte de las principales demandas de las comunidades étnicas y, en general, de las "zonas periféricas" del país. En el caso de Tumaco, los narcotraficantes comprendieron el territorio en su dimensión estratégica. Por una parte, los ríos ("donde nadie está presente") son corredores de difícil acceso y control a causa de los enormes caudales. Las selvas ofrecen cobertura para los laboratorios de procesamiento de cocaína y los estuarios proporcionan lugares idóneos para esconder los barcos y sumergibles que transportan droga y que son difícilmente detectables (Isacson, 2011). Al margen de esta circunstancia, para los habitantes de la región, la violencia sigue siendo constante y la presencia del Estado tan sólo se manifiesta con el incremento del pie de fuerza.

De acuerdo con un funcionario de la Unidad para la Atención a las Víctimas, el número de personas afectadas por la violencia en Tumaco es 100.763, es decir, casi el $50 \%$ de su población. De igual manera, según el informe de riesgo-alerta inminente de la Defensoría del Pueblo, en lo transcurrido del año 2018, 17 integrantes de la junta de gobierno del Consejo Comunitario Nueva Esperanza fueron amenazados ${ }^{9}$. Esta crítica situación es otra de las variables por las que el gobierno incluyó a Tumaco dentro de los Programas de Desarrollo con Enfoque Territorial (PDET) (Decreto 893 de 2017). La apuesta del ejecutivo es priorizar ciertos municipios del país para implementar los componentes de la Reforma Rural Integral, contemplados en

Entrevista con miembro de Consejo Comunitario de Tumaco, se omite el nombre por razones de seguridad. Entrevista realizada a funcionario de la Unidad para la Atención a las Victimas (UARIV), se omite su nombre por razones de seguridad. 
el acuerdo de paz y así dinamizar la economía de las regiones golpeadas por la violencia en aras de su integración nacional.

\section{La palma de aceite en Tumaco: una geografía del poder}

El capítulo étnico de los acuerdos de paz de La Habana contempla un reconocimiento particular de aquellas comunidades que "han sufrido condiciones históricas de injusticia, producto del colonialismo, la esclavización, la exclusión y el haber sido desposeídos de sus tierras, territorios y recursos" (Gobierno de Colombia, 2018, pp. 206-209). El propósito de este apartado dentro del Acuerdo Final es la aplicación de la perspectiva étnica y cultural respecto a lo pactado entre el gobierno y las FARC. Es un intento por integrar las aspiraciones, intereses y cosmovisiones de grupos históricamente excluidos. No obstante, este es otro de los puntos de los acuerdos de paz que han quedado suspendidos debido a la falta de planeación, estructura y recursos para llevarlos a cabo. En efecto, una de las demandas recurrentes de las comunidades étnicas es que la respuesta del gobierno es el envío de efectivos de la Fuerza Pública y la ausencia de puestos de salud o escuelas. El Consejo Comunitario de Alto Mira y Frontera fue mencionado explícitamente en el capítulo étnico como uno de los territorios priorizados a causa de los niveles de violencia y desplazamiento del que son víctimas sus habitantes.

En este sentido, los territorios de afrodescendientes han sido el escenario de disputas históricas en los que han estado involucrados diversos actores legales e ilegales -aunque estos sectores no en pocas ocasiones han estado amalgamados (Schultze-Kraft, 2016)—. Así, en municipios como Tumaco existen "dinámicas culturales que se encuentran en una lucha constante por la apropiación y la simbolización del espacio desde prácticas y representaciones disímiles" (Álvarez, 1999, p.88). Dicho esto, el segundo momento de la investigación se concentra en presentar una de las rivalidades territoriales "enmascaradas" en este municipio de Nariño: la siembra de palma de aceite como modelo productivo. Llama particularmente la atención que Tumaco es el único lugar del departamento donde hay grandes extensiones de palma. En otras regiones del país donde se encuentra este producto también se caracteriza por dos variables: la presencia de grupos armados y de cultivos de uso ilícito.

La primera planta de palma de aceite llegó a Tumaco en 1956. Como se observó en el capítulo precedente, la economía de la ciudad-puerto estuvo basada en la monoproducción primero de madera y luego de tagua. Esta tendencia continuó con la palma aceitera que pronto se convertiría en el principal producto de la zona (a pesar de la existencia de plantaciones de cacao y coco). En 1959, se fundó en Tumaco las primeras cuatro empresas dedicadas a la siembra de palma: Centro Experimental El Mira, Palmar del río, La Manigua y Palmas del Mira. Empresarios provenientes de Cali y Bogotá atraídos por las condiciones tributarias, el bajo precio de la tierra y las condiciones de mano de obra, decidieron instalar sus negocios a orillas del río Mira en tierras "baldías" que años más tarde les serían adjudicadas por el gobierno. Tan sólo ocho años después de la creación de las empresas y de las dos plantas extractoras, Tumaco contaba con 609 hectáreas lo que significaba el 5,9\% de la producción nacional (Ospina, 1998). 
Cabe advertir que el surgimiento de esta industria se dio en medio de la oposición de los habitantes que estaban en desacuerdo con la tala de manglares ${ }^{10}$. Sin embargo, el gobierno decidió impulsar el sector como una oportunidad para la creación de empleos. La representación que se configuró desde entonces fue "la idea de la palma como un cultivo que incorpora a las regiones apartadas del país al progreso económico" (García, 2011, p.218). Esta narrativa impulsó la gran empresa en Tumaco y a la par el acaparamiento de grandes extensiones de tierra. Un ejemplo de lo anterior fue la adjudicación de 1.000 hectáreas en la vereda Candelillas a los hermanos Corredor Mejía. En los inicios, los empresarios utilizaron la tierra para ganadería y la palma sólo fue empleada como medio de aislamiento frente a las "invasiones". Con el pasar de los años se fueron haciendo con más territorio a orillas del río Mira y al observar las ventajas económicas fundaron la empresa Palmeiras S.A., una de las más importantes en la actualidad (Ospina, 1998). Los hermanos Corredor compraban hectáreas de tierra a campesinos afrodescendientes e indígenas y a los que se resistían dejaban que su ganado invadiera la tierra. También empleaban topógrafos que demarcaban más hectáreas de las vendidas (Reyes, 2017). Esta y otras formas de apropiación ilegal fueron continuamente empleadas para presionar la entrega de tierras por parte de las comunidades étnicas.

Para 1974, Tumaco contaba con seis empresas dedicadas a la palma con un área sembrada cercana a las 1.177 hectáreas. Paradójicamente, el período de la gran plantación en Tumaco (1975-1981) coincidió con la crisis del sector en el ámbito nacional. A pesar de ello, en el municipio suroccidental se crearon las empresas Palmas de Tumaco y Santa Fe, y las plantas procesadoras Palmeiras y La Remigia (García, 2011, p.223). De esa manera, se fue configurando la hegemonía de la industria que para 1982 contaba con poco más de 4.600 hectáreas en el municipio. Cabe aclarar que la agroindustria palmera no acaparó todo el sector. De hecho, algunas comunidades locales tenían pequeñas o medianas plantaciones que fueron paulatinamente vendidas en los períodos de crisis. En efecto, para algunos habitantes esta fue otra forma de despojo de la tierra pues debido a las condiciones económicas y a la falta de apoyo estatal las deudas hacían que los campesinos hipotecaran sus tierras que serían finalmente absorbidas por las grandes empresas de la región.

En línea con lo anterior, debe mencionarse el papel que cumplieron las "alianzas estratégicas" entre campesinos, Consejos Comunitarios y empresas palmicultoras, respaldadas por el gobierno colombiano (particularmente bajo la administración de Andrés Pastrana 1998-2002). En este marco, surgió una suerte de "multiculturalismo verde", como lo denomina Roosbelinda Cárdenas (2012), sistema que actúa como tecnología disciplinaria que busca transformar las racionalidades locales en empresariales. En consecuencia, las "alianzas estratégicas" constituyeron un intento más de involucrar a la población local en la geografía del poder, no ya desde la coerción sino desde la cooptación. Así, los Consejos Comunitarios no emergen simplemente como víctimas exclusivas de las violencias de la región, sino además como un aparato sujeto de dominación por parte de una lógica de producción neoliberal.

En el período comprendido entre 1982 y 1990, se crearon tres nuevas empresas: Palmar de Santa Helena en la vereda La Espriella — donde funcionaban otras compañías-; Astorga S.A, propiedad de los hermanos Varela quienes sembraron 1.900

10 Esta idea se soporta en los estudios de Hoffmann (2004), Arboleda (2008) y Reyes (2017), así como de los testimonios recogidos durante la investigación. 
hectáreas de palma, pero a quienes fueron adjudicadas un total de 4.500 entre los ríos Caunapí y Rosario; y, por último, Palmas Oleaginosas Salamanca a siete kilómetros del río Mira (Ospina, 1998). A propósito de este fenómeno, la mayor parte de la industria de palma se ubicó estratégicamente al borde del río Mira donde sacaban la producción hacia el puerto de Tumaco. Estas mismas rutas serían utilizadas años más tarde para el tráfico de estupefacientes.

Así pues, a finales de los años noventa, la industria palmera en Tumaco contaba con nueve empresas y cinco plantas extractoras donde se procesaban el fruto de 12.000 hectáreas sembradas (García, 2011), aunque otras cifras hablan de cerca de 20.000 hectáreas para el mismo período de tiempo. El telón de fondo en el que se daba esta circunstancia era el proceso de adjudicación de títulos colectivos a los Consejos Comunitarios según lo estipulaba la ley 70 de 1993, hecho que estuvo marcado por trabas administrativas e intereses involucrados (Agier et al., 1999). Con todo, a partir de 1998 se iniciaron los procesos de titulación colectiva, pero en medio de intimidaciones, amenazas y asesinatos a líderes afrocolombianos. De hecho, "se construyeron rentas a partir del despojo o la confiscación de tierras, legalizadas o no, que suscitaron enfrentamientos entre propietarios de plantaciones y campesinos negros" (Agier y Hoffmann, 1999, p.56). El asesinato del líder Francisco Hurtado Cabezas por su papel en las denuncias promovidas por la contaminación del río Mira a causa de la producción de palma y por una superposición de intereses en los que Palmeiras S.A. buscaba 800 hectáreas en la vereda Candelillas que eran pretendidas por el Consejo de Alto Mira y Frontera, demuestran la complejidad de la problemática.

El desarrollo de los cultivos de palma y en general del sector económico en el que se apoyó no hubieran sido posible sin el respaldo de diversos sectores políticos. La reducción de impuestos y el precio de la tierra motivó a los empresarios a iniciar con el monocultivo que fue promovido, con distintas intensidades, por todos los gobiernos desde la década de 1950. En otros términos, ninguna administración se opuso a los efectos colaterales de acaparamiento de tierras y desplazamiento de población que la industria generaba.

La década de 1990 fue probablemente la que más impacto trajo para los intereses de los grandes palmicultores, comenzando con el gobierno de César Gaviria (19901994). De una parte, por la promoción de un modelo que estimulaba la inversión extranjera y las importaciones. Por otra, la promulgación de la Constitución de 1991 que reconocía, por primera vez, los derechos territoriales de las comunidades ne$\operatorname{gras}^{11}$. Esto en la práctica significó un solapamiento de intereses, pues las empresas palmeras ya tenían instaladas grandes plantaciones en territorios que serían adjudicados a las comunidades étnicas. De ese modo, "el cultivo fue considerado como un instrumento para legalizar la propiedad de la tierra, mantener un negocio legal lucrativo, establecer un control estratégico sobre el territorio y lavar dinero proveniente del narcotráfico" (Segura y Maldonado, 2009, p.22). La hipótesis defendida por estos investigadores es que el cultivo de la palma incentiva el desplazamiento para que las empresas puedan apoderarse del uso y explotación de la tierra. En esta misma vía, se orientan los trabajos de Escobar (2016), Cárdenas (2012), Oslender (2008, 2004), Hoffmann (2007) y Restrepo (2004). Estos conflictos, sin embargo, buscan ocultarse

11 Para una referencia sobre la paradoja del neoliberalismo económico promovido por el gobierno de Cesar Gaviria y la promulgación de los derechos de los grupos étnicos, ver Orjuela (1998). 
por acción del gobierno nacional cuya representación es convertir al aceite de palma en un sector idóneo para el "crecimiento económico del país".

En efecto, fue en el gobierno de Andrés Pastrana (1998-2002) donde los industriales de este sector tuvieron un respaldo definitivo. El nombramiento del empresario de la palma Carlos Murgas Guerrero como ministro de Agricultura y Desarrollo Rural puso en evidencia la estrecha relación entre el poder político y este negocio agroindustrial. En palabras del propio ministro, las plantaciones de palma ofrecían una excelente oportunidad "para desarrollar el agro colombiano, erradicar la pobreza, controlar la violencia y resolver el gravísimo problema social que desde tiempos inmemoriales sacude y atormenta al campo colombiano" (Murgas, 1999, pp.8892). No obstante, esta representación del "progreso y desarrollo" no corresponde con la realidad de lugares como Tumaco. De hecho, la siembra de palma profundizó las relaciones de desigualdad, promovió el acaparamiento de tierras y trajo consigo más tensiones por el uso del territorio que soluciones prácticas a la economía de los sectores más vulnerables del país.

Con todo, el presidente Pastrana y el ministro Murgas promovieron las "alianzas productivas para la paz" antes mencionadas, proyecto que se basaba en el otorgamiento de recursos a las empresas regionales en aras del interés social y la integración de la sociedad civil en los proyectos económicos. Empero, esto se convirtió en una nueva tendencia de despojo pues los recursos llegaron a manos de los industriales y no a las comunidades. El apoyo del gobierno fue tal que en un viaje a Malasia - en ese entonces primer productor de palma de aceite-, el presidente Pastrana aseguró que Colombia disponía de más de tres millones de hectáreas para la siembra de palma, además de contar con los equipos técnicos y los recursos humanos necesarios para promover las inversiones en el sector. Esta tendencia llevó a que los cultivos de palma en Tumaco registraran entre 1999 y 2007 un crecimiento total del 164, 8\%. En efecto, de acuerdo con datos de Fedepalma pasaron de ocupar 20.996 hectáreas en 1999 a 34.416 en 2007 (Alfonso, Grueso y Prada, 2011, p.29).

El aumento en los cultivos y en general el apoyo al sector industrial de la palma se profundizó bajo las dos administraciones de Alvaro Uribe (2002-2010). De hecho, en el Plan Nacional de Desarrollo 2006-2010 se estableció un marco de incentivos tributarios y financieros para la promoción del mercado de biocombustibles. No obstante, la directriz del gobierno Uribe se dio en medio de la afectación de los cultivos de palma con un hongo que produce una enfermedad conocida como la pudrición del cogollo. Este fenómeno se inició en Tumaco hacia 2004 y se estima que destruyó 30.000 hectáreas de plantaciones. Aunque no ha podido ser comprobado, para habitantes y algunos empresarios existe una correlación entre la propagación de la enfermedad y la intensificación de las fumigaciones aéreas con glifosato que acabaron también con los cultivos lícitos (Rico, 2010). A pesar del devastador panorama para la agroindustria de la palma, el gobierno optó por promover nuevas plantaciones.

En este marco se produjo uno de los mayores escándalos de corrupción durante la administración de Uribe. El ministro de agricultura Andrés Felipe Arias, fue destituido e inhabilitado por 16 años para ejercer cargos públicos por la Procuraduría y hallado culpable por la Corte Suprema de Justicia por delitos de celebración de contratos sin cumplimiento de requisitos legales y peculado a favor de terceros. Por estas conductas, fue condenado a 17 años y 4 meses de prisión, pero no aceptó los cargos y hoy se adelanta un proceso en su contra. El pliego de cargos fue formulado en relación al programa "Agro Ingreso Seguro" que consistió en desvíos de subsidios 
destinados a campesinos pobres que favorecieron a acaudalados hacendados e incluso a narcotraficantes (El Espectador, 2009). En el caso específico de la palma, el Ministerio de Agricultura otorgó 27.600 millones de pesos (8,1 millones de euros), de los cuales solo una empresa, Palmeros del Pacífico Sur, recibió más del 15\% del total. Esta empresa ubicada en Tumaco obtuvo más dinero que todos los beneficiarios en cualquier departamento (Lewin, 2009). De igual manera, empresas de palma pertenecientes al grupo económico Sarmiento Angulo, uno de los más poderosos del país, recibió una ayuda cercana a los 4.000 millones (1,2 millones de euros). Estos son sólo algunos de los escándalos que desató el financiamiento ilegal promovido desde el Ministerio de Agricultura, pues también se demostró que los beneficiarios fueron personas y grupos que respaldaron económicamente las dos candidaturas a la presidencia de Álvaro Uribe (Coronell, 2010). A pesar de estas circunstancias y de la relación de la agroindustria de la palma con el acaparamiento de tierra, hoy sigue siendo uno de los principales rubros de la economía en el país y particularmente del municipio de Tumaco.

Este panorama general da cuenta de una relación estrecha entre el poder público y los empresarios de la palma en detrimento de algunas de las comunidades étnicas en Colombia. En este sentido, puede establecerse una correlación entre el desplazamiento forzado en el país y la siembra de palma de aceite (Rey, 2013), hecho que ha impactado de manera particular a grupos afrodescendientes y comunidades indígenas. Al mismo tiempo, esta circunstancia rompe con la lógica binaria entre narcotráfico (ilegalidad, violencia y desplazamiento) y palma de aceite (legalidad, productividad y crecimiento), pues bajo el abrigo de negocio aparentemente lucrativo y legal, se esconde un doble ejercicio de cooptación y violencia que es lo que algunas instituciones del Estado pretenden enmascarar ${ }^{12}$.

\section{Ocupaciones y desplazamientos}

Las causas actuales del desplazamiento en Tumaco se relacionan directamente con la presión de los grupos armados que hostigan a la población a la entrega de sus tierras o al reclutamiento de jóvenes para engrosar las estructuras criminales. Sin embargo, el tema de desplazamiento en el municipio no es nuevo. En efecto:

Entre 1950 y 1970 se vivió una fuerte degradación en las formas de vida. Luego de La Violencia que desalojó de la región a muchos campesinos, otros tantos perdieron sus tierras en beneficio de las plantaciones agroindustriales de palma africana controladas por empresarios originarios de Cali, Bogotá o del extranjero. Fuera porque no tenían títulos legalizados, fuera porque se endeudaron para la modernización agrícola y perdieron sus tierras dadas en garantías hipotecarias de los créditos indispensables, fuera que sencillamente tuvieron que ceder ante el avance de la maquinaria de las plantaciones, hoy los campesinos desplazados se encuentran en su mayoría en la ciudad de Tumaco, cuyo crecimiento en los últimos quince años se debe en gran parte a este éxodo rural (Agier y Hoffmann, 1999, p.64).

12 Para profundizar sobre el fenómeno ver Hoffmann (2007, capítulo 7, pp.167-178). 
En este sentido, según un informe del sistema de alerta temprana de la Defensoría del Pueblo (2008), la expansión de cultivos de palma durante la década de 1970 incentivó la aparición de un grupo armado ilegal autodenominado La escoba que se encargó de realizar "limpieza social", asesinando a campesinos y labriegos estigmatizados como indeseables y que se oponían a los proyectos productivos. Esta podría ser una de las causas por las cuales el rendimiento de la palma en Tumaco tuvo un aumento considerable entre 1975 y 1981 que coincide con el período de crisis en el ámbito nacional. Con el despojo a los pequeños propietarios, la agroindustria tomó un impulso notable que se acompañó de la inversión privada y el respaldo estatal. Ello explica también por qué hasta entrada la década de los 1990, la mayor parte de las empresas palmeras no tenían legalizados sus títulos de propiedad.

El desplazamiento forzado a la zona urbana fue progresivo y coincide con el periodo de la primera plantación de palma de aceite. Si bien no hay una relación sistemática que pruebe un nexo causal entre las plantaciones de palma y los éxodos de la población, existen diversos estudios que plantean al menos una correlación ${ }^{13}$. En este sentido, los resultados de la investigación econométrica del profesor Camilo Rey muestran una correspondencia positiva entre desplazamiento forzado y la expansión de la palma de aceite que ocurrió en los nuevos municipios palmeros y zonas de mayor expansión del cultivo (Rey, 2013, p.716). De esa manera,

en términos porcentuales, aunque sólo el 8,2\% de los municipios colombianos siembran palma, en ellos ocurrió el $22,4 \%$ de las expulsiones de población (...) mientras que en los municipios sin cultivos de palma entre 2002 y 2009 se desplazaron a 85 personas por cada cien mil habitantes, en aquellos con cultivos la tasa fue de 181 personas (Rey, 2013, p.701).

Por esa razón, la geografía de la palma de aceite tiene algún tipo de relación con el desplazamiento y la expoliación de tierras a las comunidades como ha sido su denuncia histórica.

Aunque no puede comprobarse que la agroindustria palmera haya suscitado la violencia directa contra las poblaciones vulnerables, de acuerdo con testimonios de desmovilizados de grupos armados (principalmente paramilitares), los empresarios contribuyeron en el financiamiento de estos ejércitos ilegales (Molano, 2012). En efecto, con la llegada de las guerrillas que generalmente cobraban extorsiones a los empresarios, los grupos paramilitares simbolizaron una suerte de "seguro territorial". Cabe advertir que, desde la perspectiva económica, el desplazamiento de la población y la violencia misma significan un medio por el cual se abarata el precio de la tierra y no es problemático imponer mecanismos de producción de recursos legales o ilegales ya sean en servicio de un grupo armado o de la élite terrateniente local (Rey, 2013, pp.688-689). Por ese motivo, como lo expresa Carlos Rosero, representante de las comunidades negras:

el desplazamiento forzado interno es funcional, no sólo a la guerra, sino también al avance de los megaproyectos y los cultivos que, como la palma aceitera,

13 Entre los estudios cualitativos están los trabajos de Arboleda (2008) en Tumaco, Hurtado y Hernández (2010) en el Cesar, Goebertus (2008) en la Zona Bananera y García (2011) y Oslender (2008) en el Pacífico. 
avanzan con el apoyo del gobierno nacional al norte y al sur del territorio del Pacífico (Carrere, 2006, p.50).

Esta realidad muestra que los cultivos de uso ilícito sólo son una problemática más en un complejo entramado de rivalidades por el territorio en Tumaco.

Al respecto, uno de los lugares comunes más poderosos y ampliamente difundidos a través de organizaciones políticas, medios de comunicación e incluso la cultura popular (representación construida) es la relación de la coca con los países andinos y específicamente con Colombia. Tumaco, por supuesto, no escapa a esta lógica, pero si se considera que los cultivos de uso ilícito son un escenario relativamente reciente en el municipio, ¿por qué el conflicto ha sido permanente? Parte de la respuesta al cuestionamiento es la función enmascaradora del tráfico de estupefacientes con respecto a las relaciones clasistas, de expropiación y explotación que son ocultadas bajo la narrativa de la "lucha contra las drogas".

Además de lo anterior, resulta curioso que los primeros grupos narcotraficantes no despojaron de sus tierras a los empresarios, sino que por el contrario establecieron alianzas que contaron con la protección posterior de los grupos paramilitares (Agier y Hoffmann, 1999). De acuerdo con un estudio del profesor Hernando Zuleta, los municipios cocaleros son en promedio más pobres que el resto de municipios del país pues tienen ingresos tributarios bajos, pocos niveles de conectividad y bajo desarrollo institucional (Zuleta, 2017) ${ }^{14}$. Esto se debe principalmente a que los campesinos no cuentan con alternativas económicas para remplazar su actividad cocalera. Sin embargo, dejando de lado la variable del narcotráfico, aún persisten las tensiones geopolíticas por el acceso y control en la tierra. De alguna manera, el tráfico de drogas se ha convertido en una explicación unidimensional que encubre otro tipo de tensiones. Si bien no debe escatimarse que el fenómeno de la coca se identifica como uno de los mayores problemas de las comunidades afrodescendientes en los territorios colectivos, debe considerarse la imbricación de la violencia que surge con la siembra de monocultivos de palma de aceite. En otras palabras, no son situaciones contradictorias, sino complementarias.

Para mostrar que el narcotráfico es tan sólo un catalizador del conflicto y no su causa principal está el factor oro. De acuerdo con el investigador Carlos Montoya, si bien desde 2014 ha existido un aumento sostenido de los cultivos de uso ilícito, entre 2009 y 2012 sufrieron una baja importante. Así pues:

Si se miran los mapas de los territorios donde hay cultivos de uso ilícito y donde hay minería ilegal, hubo una subida general del precio del oro en esos años en que bajaron los cultivos, lo que indica que las personas que se dedicaban a ellos se desplazaron hacia la minería; dieron un salto a un negocio más rentable en ese momento (Montoya, cit. en El País, 2017).

Desde esta perspectiva, el narcotráfico se percibe como un método de financiación para las actividades delictivas o un medio de sustento para ciertas poblaciones

14 El profesor Zuleta tiene otros estudios en los que sostiene que la hoja de coca sólo representa el 9\% del problema del narcotráfico. Por eso argumenta que para reducir la oferta mundial de cocaína son más eficientes los esfuerzos en incautaciones y destrucción de infraestructura que las acciones dirigidas a la erradicación de la hoja de coca. 
vulnerables y no como el epicentro de las tensiones territoriales en Tumaco. En otras palabras, este fenómeno constituye uno más de los complejos escenarios que se encuentran entretejidos pero que ocupa, sin embargo, el primer orden de importancia en la agenda del gobierno.

Por otra parte, es necesario destacar que la geografía de los cultivos de palma y aquella de las plantaciones de hoja de coca presentan ciertas similitudes. Al menos dos zonas del país tienen estas características: el departamento de Norte de Santander en la frontera con Venezuela y el departamento de Nariño que comparte límites con Ecuador y el océano Pacífico. Debido a su posición geoestratégica esos dos nodos albergan grandes extensiones de cultivos de palma de aceite y coca. En efecto, Tumaco concentra el $16 \%$ de la producción de hoja de coca en el país, seguido del municipio de Tibú en el Norte de Santander con 9\% de la producción total (El Tiempo, 2017). Las condiciones climáticas de selva tropical, sumada a la naturaleza de zonas porosas y la presencia de grupos armados hace de estos municipios lugares esenciales para el control territorial. En los departamentos de Bolívar, Chocó, Córdoba, Antioquia y Meta también se presenta una imbricación de estos cultivos. Sin embargo, hay zonas del país donde no es evidente la relación. Por ejemplo, en Cesar, Magdalena, Sucre y Cundinamarca hay importantes plantaciones de palma de aceite y no así de cultivos de uso ilícito (pero sí presencia de grupos armados). Caso contrario de los departamentos de Putumayo, Caquetá, Guaviare y Vichada donde hay sembrada hoja de coca, pero no palma de aceite.

Por esa razón, aunque no puede establecerse una correlación directa entre la palma y la producción de hoja de coca, sí existe un nexo entre las condiciones sociales y políticas que rodean la siembra de estos productos. En otras palabras, los cultivos no son incompatibles y de hecho pueden servir para propósitos similares. En efecto, con la llegada de los primeros narcotraficantes a Tumaco, la agroindustria palmera no fue percibida como un problema sino al contrario como una oportunidad de negocio. Así, algunos narcotraficantes utilizaban las empresas palmeras como "fachadas" para lavar los dólares de la actividad ilegal (Escobedo y Palacios, 2009). De igual manera, algunos empresarios incursionaron en el tráfico de estupefacientes, razón por la cual no hubo una superposición de intereses.

En consecuencia, los agroindustriales y, más recientemente, los narcotraficantes expulsaron a los habitantes de sus tierras ancestrales, desplazándolos en su mayoría a la zona urbana del municipio o, en algunos casos, empleándolos en sus actividades. En relación con esto, debe mencionarse un fenómeno reciente en la figura del "secuestro colectivo" al que está sometida la población local, pues los grupos ilegales, en connivencia con sectores industriales y políticos, han prohibido cualquier salida definitiva del territorio a miles de personas, haciendo que estén prisioneros en sus propias tierras, pero trabajando bajo presión en algún negocio ilegal (Hoffmann, 2007, p.174-175).

De esa manera, según un estudio del Centro Nacional de Memoria Histórica, los cultivos de palma de aceite se relacionan con: a) impactos ambientales negativos por el predominio del monocultivo; b) el desplazamiento de prácticas agrícolas y pesqueras de las poblaciones; c) incremento de los cultivos ilícitos en áreas de conflicto armado y d) despojo de tierras en algunas zonas del país (CNMH, 2016, p.462). La presencia de grupos paramilitares so pretexto de combatir la influencia de las guerrillas, "sirvió para el desplazamiento masivo de la población rural y la ampliación de tierras para el incremento de la producción de aceite de palma, pero entre las 
fracturas del despojo, también para el incremento de la producción de cocaína" (Reyes, 2017, p.43). Con la llegada de los cultivos de uso ilícito y de los grupos armados a Tumaco, el crecimiento de las hectáreas de palma fue constante, lo que quiere decir que no afectó de manera significativa la siembra de coca a las empresas palmeras.

Este escenario muestra que las comunidades vulnerables están influidas por ambas circunstancias. De una parte, las empresas de palma de aceite presionan para la venta de tierras, otorgan trabajos con bajos salarios o contratan colonos que de a pocos se hacen con porciones de tierra que corresponden a los Consejos Comunitarios (Restrepo, 2004). De otro lado, están los grupos narcotraficantes que obligan a los habitantes a mantener las hectáreas de cultivos de uso ilícito para aumentar la producción de cocaína y se encuentran secuestrados en sus propios territorios (Hoffmann, 2007). No obstante, estas dos formas de presión no son incompatibles sino complementarias y a nuestro juicio cumplen la función de enmascarar una compleja realidad. En efecto, debido a su carácter ilegal, el narcotráfico es perseguido como la actividad que genera mayor índice de violencia y desplazamiento, pero lo mismo ocurre con el negocio de la palma que goza, no obstante, de un estatus diferente por constituir una de las actividades más lucrativas en la región.

De hecho, el negocio de la palma de aceite no sólo es más antiguo, sino que además tiene una influencia directa con el despojo de tierras a comunidades y el éxodo de campesinos, afrocolombianos e indígenas (Agier y Hoffmann, 1999; Rey, 2013; Angulo, 1996; Oslender 2008; Cárdenas 2012). Por ese motivo, "los impactos ambientales y sociales que ha causado la palma en el Pacífico pueden ser iguales o peores a los que generan los cultivos de uso ilícito" (Arboleda, 2008, p.123). La diferencia radica que, en tanto representación construida, la palma de aceite no es percibida desde el alto gobierno como causante de conflictos territoriales sino como una solución al tema de los cultivos de uso ilícito. Cabe agregar que en al menos cinco departamentos del país existe "una relación directa entre el desplazamiento, abandono y cultivo de palma de aceite" (CNMH, 2016). Según el Centro de Memoria Histórica, en Bolívar, Magdalena, Chocó, Cesar y Nariño (particularmente la ronda del río Mira, Tumaco), las tierras que pertenecieron a los campesinos y comunidades negras fueron sembrados con palma y ello provocó el desplazamiento de miles de personas.

\section{Consideraciones finales}

El artículo buscó presentar algunos elementos esenciales en la discusión sobre los tensiones territoriales en Tumaco, uno de los municipios más afectados por el conflicto armado en Colombia. Si bien el narcotráfico ha sido un fenómeno complejo que ha agudizado el despojo y la vulneración de los derechos humanos, es también un asunto relativamente reciente en el suroccidente del país. Con ese propósito en mente, el trabajo intentó demostrar que el tráfico de estupefacientes es utilizado como un medio "enmascarador" - para utilizar las palabras del profesor Yves Lacoste- por parte del Estado colombiano con el objetivo de ocultar otras rivalidades más hondas y antiguas. En efecto, el acaparamiento de tierras por distintos medios y estrategias se produjo en Tumaco desde la década de 1950 con la llegada de industriales extranjeros y de la zona andina que promovían conectar la ciudad-puerto con el centro del país. Eso sin contar la serie de despojos llevada a cabo con la 
declaratoria de las "tierras baldías" y la historia de explotación y esclavismo que durante dos siglos padecieron sus habitantes.

Desde esta perspectiva, la agroindustria de palma de aceite se convirtió en un negocio rentable, cuyo crecimiento se debió al menos a dos factores. En primera medida, el decidido apoyo del poder político en Colombia que bajo el régimen de las excepciones fiscales y amparado en la idea de promover "el desarrollo en las zonas periféricas del país", otorgó grandes extensiones de tierras a los industriales. El segundo elemento, se relaciona con el apoyo soterrado de grupos paramilitares que, en diversas regiones del país (Tumaco entre ellas), desplazaron a los pobladores mediante acciones violentas, favoreciendo los intereses de los empresarios de la palma y que en la actualidad, siguiendo a la investigadora Odilie Hoffmann (2007), han promovido un régimen de "secuestro colectivo" en sus propios territorios.

En esta misma línea, el narcotráfico, desde la perspectiva del actual gobierno (y la mayoría de sus antecesores), tiene un papel dominante en las explicaciones del conflicto por encima de otras causas estructurales como la tierra y la exclusión política. La imbricación de fenómenos ha permitido la creación de relatos homogéneos. Particularmente, en los dos mandatos de Álvaro Uribe se propagó el relato de que las FARC eran una amenaza "narcoterrorista" y que la solución debía encontrarse por la vía militar - hoy el argumento es el mismo, pero aplicado a las disidencias de las FARC y al ELN-. De esa forma, durante ocho años se negó el problema de la tenencia de la tierra y la exclusión en política de sectores vulnerables como causas que prolongaron el conflicto. En este periodo, se registraron más de seis millones de víctimas, cuatro millones de desplazados y los asesinatos extrajudiciales conocidos como "falsos positivos" que, según el periódico The Guardian (2018) llegaron a 10.000 .

Sin embargo, es claro que el narcotráfico sigue siendo uno de los motores de la violencia en el país, razón por la cual, el programa de sustitución de cultivos ilícitos tiene un gran desafío. La presente investigación, por tanto, puede sentar las bases para un futuro estudio más detallado sobre la correlación ya no del desplazamiento y la siembra de palma de aceite, sino entre ésta y la siembra de hoja de coca. Así las cosas, aunque no pueda generalizarse, es posible reconocer un patrón similar entre la siembra de monocultivos - que en todo caso alientan la concentración de la tierra- y el negocio del narcotráfico, pues como se mostró no son actividades antagónicas. En este punto, se produce una amalgama entre violencia, legalidad, ilegalidad y negocio que desdibujan en buena medida las fronteras entre el narcotráfico y el monocultivo de palma, por lo que este último enmascara las relaciones de dominación por parte de actores crimilegales (Schultze-Kraft, 2016) en detrimento de las comunidades étnicas. Sin embargo, las estrategias son diversas y varían entre la coerción y la cooptación de la población.

Los desafíos de cara a la implementación de los acuerdos de La Habana son múltiples y desbordan el contenido mismo de este artículo. En ese sentido, el hecho de que Tumaco sea uno de los municipios prioritarios para el desarrollo de las reformas, hace pensar que la construcción de una "paz estable y duradera" incluye auténticos cambios en la distribución de la tierra, lo que pasa por fuertes tensiones geopolíticas que pretendieron ser explicadas en el desarrollo de las reflexiones propuestas. De hecho, más allá de los detalles técnicos y sociológicos, la problemática en Tumaco posee una fuerte raíz geopolítica que está mediada por una gama diversa de intereses y representaciones. Para las comunidades está en juego el cumplimiento de lo 
acordado en La Habana pues de ello dependerá un posible recrudecimiento de la violencia por parte de los actores que presionan para continuar con la producción de hoja de coca. Aunque como vimos, existe también una perspectiva crítica sobre el Acuerdo a causa de la exclusión de los sectores más afectados (Caicedo, 2016). El problema mayor lo constituye el hecho de que los acuerdos de paz entraron en un terreno de incertidumbre a causa de la postura ambivalente del gobierno de Iván Duque sobre su cumplimiento, y mientras se discuten los detalles políticos en Bogotá, en municipios como Tumaco, la violencia sigue siendo la moneda de cambio.

\section{Agradecimientos}

El autor agradece los comentarios de las personas que revisaron el artículo.

\section{Referencias}

Agier, M. (1995). Lugares y redes. Las mediaciones de la cultura urbana. Revista Colombiana de Antropología, (22), 219-243.

Agier, M. et al. (1999). Tumaco: haciendo ciudad: historia, identidad y cultura. Cali: ICAN, IRD, Universidad del Valle.

Agier, M., y Hoffmann, O. (1999). Las tierras de las comunidades negras en el Pacífico colombiano: interpretaciones de la ley, estrategias de los actores. Territorios, Revista de Estudios Regionales y Urbanos, (2), 53-76.

Albaladejo, A., y Haugaard, L. (2016). Los costos en derechos humanos durante el plan Colombia. Latin America Working Group. Recuperado de https:/coeuropa.org.co/los-costos-en-derechos-humanos-durante-el-plan-colombia-infografia/

Alfonso, T.; Grueso, L., y Prada, M. (2011). Estudios de caso: desarrollo y conflictos de tierras. Caso 1 Alto Mira y Frontera. En T. Alfonso et al., Derechos enterrados. Comunidades étnicas y campesinas en Colombia, nueve estudios de caso (pp. 29-46). Bogotá: Universidad de los Andes, USAID.

Álvarez, M. (1999). La ciudad deseada: seducciones y artilugios del desarrollo. En M. Agier et al., Tumaco: haciendo ciudad. Historia, identidad y cultura (pp. 86-13). Cali: Instituto Colombiano de Antropología, Universidad del Valle.

Angulo, N. (1996). Los impactos socioculturales causados por las industrias palmicultoras y camaroneras en el municipio de Tumaco. Tumaco: Proyecto Biopacífico.

Arboleda, N. (2008). La palma africana en el Pacífico colombiano: su legalidad, consecuencias y violación de derechos territoriales. Revista Luna Azul, (27), 113-126.

Arocha, J. (ed.). (2004). Utopía para los excluidos: el multiculturalismo en África y América Latina. Bogotá: CES, Universidad Nacional de Colombia.

Basset, Y. (2018). Claves del rechazo del plebiscito para la paz en Colombia. Estudios Políticos (Universidad de Antioquia), 241-265. https://doi.org/10.17533/udea.espo.n52a12

Caicedo, J. (2016). Conflictos por el uso del suelo: territorios indígenas y afrodescendientes. Bitácora Urbano Territorial, 26 (2), 87-89. https://doi.org/10.15446/bitacora.v26n2.59294

Cárdenas, R. (2012). Green multiculturalism: articulations of ethnic and environmental politics in Colombian "black community". The Journal of Peasant Studies, 39(2), 309-333. 
Carrere, R. (coord.). (2006). Palma aceitera: de la cosmética al biodiesel. La colonización continúa. Montevideo: Rel-ultra.

CNMH (Centro Nacional de Memoria Histórica). (2016). Tierras y conflictos rurales. Historia, politicas agrarias y protagonistas. Bogotá: CNMH.

CNMH (Centro Nacional de Memoria Histórica). (2015). Desmovilización y reintegración paramilitar. Panorama posacuerdos con las AUC. Bogotá: CNMH.

Coronell, D. (2010). El pastorcito. Revista Semana, 2 de octubre. Recuperado de https://www.semana.com/opinion/articulo/el-pastorcito/108240-3

DANE (Departamento Administrativo Nacional de Estadística). (2018). Estimación y proyección de población nacional, departamental y municipal total por área 1985-2020. Recuperado de https:/www.dane.gov.co/index.php/estadisticas-por-tema/demografia-y-poblacion/proyecciones-de-poblacion

Defensoría del Pueblo (Colombia) (2008). Defensoría delegada para la evaluación de riesgos de la población civil como consecuencia del conflicto armado (sistema de alertas tempranas). Informe de riesgo $n^{\circ} 02908,4$ de diciembre.

De Friedemann, N. (1993). La saga del negro: presencia africana en Colombia. Bogotá: Pontificia Universidad Javeriana.

De Friedemann, N. (1989). Criele criele son del Pacifico negro. Arte, religión y cultura en el litoral del Pacifico. Bogotá: Editorial Planeta.

De Friedemann, N., y Arocha, J. (1986). De sol a sol: génesis, transformación y presencia de los negros en Colombia. Bogotá: Editorial Planeta.

El Espectador (2009). Agro Ingreso Seguro habría favorecido a narcos. El Espectador, 8 de octubre. Recuperado de https://www.elespectador.com/noticias/politica/articulo165592agro-ingreso-seguro-habria-favorecido-narcos

El País (2017) ¿Por qué se disparó la siembra de coca en Colombia? El País.com.co, 23 de julio. Recuperado de http://www.elpais.com.co/colombia/por-que-se-disparo-la-siembrade-coca-en.html

El Tiempo (2017). Historia de Tumaco podría repetirse en otros nueve municipios. El Tiempo, 18 de octubre. Recuperado de http://www.eltiempo.com/politica/proceso-depaz/municipios-con-mayoria-de-hectareas-de-coca-en-riesgo-de-ataques-como-el-de-tumaco-142554

Escobar, A. (2016). Territorios de diferencia. Lugar, movimientos, vida, redes. Popayán: Editorial Universidad del Cauca.

Escobar, A. (2014). La invención del desarrollo. Popayán: Editorial Universidad del Cauca.

Escobedo, L., y Palacios, M. (2009). Dinámica reciente de la violencia en la costa pacífica nariñense y caucana y su incidencia sobre las comunidades afrocolombianas. Bogotá: Observatorio del Programa Presidencial de Derechos Humanos y DIH.

García, P. (2011). La paz perdida. Territorios colectivos, palma africana y conflicto armado en el Pacífico colombiano. Tesis doctoral en Ciencias Sociales, FLACSO México, México.

Gobierno de Colombia (2018). Acuerdo final para la terminación del conflicto y la construcción de una paz estable y duradera. Recuperado de http://www.altocomisionadoparalapaz.gov.co/

Goebertus, J. (2008). Palma de aceite y desplazamiento forzado en Zona Bananera: "trayectorias" entre recursos naturales y conflicto. Colombia Internacional, (67), 152-175. https://doi.org/10.7440/colombiaint67.2008.07

Hoffmann, O. (2007). Comunidades negras del Pacífico colombiano. Innovaciones y dinámicas étnicas. Quito: Ediciones Abya-Yala. 
Houghton, J. (ed.) (2008). La tierra contra la muerte. Conflictos territoriales de los pueblos indigenas en Colombia. Bogotá: CECOIN.

Hurtado, M., y Hernández-Salazar, G. (2010). Perfil local y agroindustria palmera: explorando el caso de San Alberto y San Martín (Cesar). Cuadernos de Desarrollo Rural, 7(65), 125-145. https://doi.org/10.11144/Javeriana.cdr7-65.plap

Isacson, A. (2011). En la convulsionada Tumaco, pocos avances. Instituto para el desarrollo y la paz (INDEPAZ). Recuperado de http://ccai-colombia.org/2011/06/09/en-la-convulsionada-tumaco-pocos-avances-2/

Lacoste, Y. (1976). La géographie, ça sert d'abord à faire la guerre. París: Flammarion.

Lewin, J. (2009). Palma, ingreso seguro. La Silla Vacía, 6 de octubre. Recuperado de http://lasillavacia.com/historia/4627

Molano, A. (2012). Paramilitarismo y palma en el Catatumbo. El Espectador, 3 de marzo. Recuperado de https://www.elespectador.com/noticias/judicial/paramilitarismo-ypalma-el-catatumbo-articulo-330074

Murgas, C. (1999). La agroindustria de la palma de aceite y sus retos para el futuro de Colombia. Palmas, 20(2), 88-92.

Orjuela, L. (1998). El Estado colombiano en los noventa: entre la legitimidad y la eficiencia. Revista de Estudios Sociales, (1), 56-60. https://doi.org/10.7440/res1.1998.08

Ortiz, O. (2018). El SOS en Tumaco. UN periódico digital, 22 de enero. Recuperado de https:/unperiodico.unal.edu.co/pages/blog/detail/el-sos-en-tumaco/

Oslender, U. (2008). Comunidades negras y espacio en el Pacifico colombiano. Hacia un giro geográfico en el estudio de los movimientos sociales. Bogotá: Instituto Colombiano de Antropología e Historia.

Oslender, U. (2004). Geografías de terror y desplazamiento forzado en el Pacífico colombiano: conceptualizando el problema y buscando respuestas. En E. Restrepo y A. Rojas (eds), Conflicto e (in)visibilidad: retos en los estudios de la gente negra en Colombia (pp. 35-52). Popayán: Universidad del Cauca.

Ospina, M. (1998). La palma africana en Colombia: apuntes y memorias (vol. 2). Bogotá: Fedepalma.

Palma, M. et al. (2014). Tumaco: ¿Razones para la desesperanza? Bogotá: OPEAL, ICP, Fedepalma.

Restrepo, D. (2018). Tumaco, un posconflicto armado. Razón Pública, 22 de enero. Recuperado de https://www.razonpublica.com/index.php/regiones-temas-31/10828-tumaco,-unposconflictoarmado.html

Restrepo, E. (2004). Hacia una etnografía del cultivo de la palma africana en Tumaco. Universitas humanística, (58), 80-83.

Restrepo, E. (1999). Hacia la periodización de la historia de Tumaco. En M. Agier et al., Tumaco: haciendo ciudad. Historia, identidad y cultura (pp. 55-86). Cali: Instituto Colombiano de Antropología, Universidad del Valle.

Rey, C. (2013). Análisis espacial de la correlación entre cultivo de palma de aceite y desplazamiento forzado en Colombia. Cuadernos de Economía, 32(61), 638-718.

Reyes, J. (2017). Despojo de territorios o reconocimiento de la tierra: coca, palma y poder en el consejo comunitario de alto mira y frontera, Tumaco. TraHs, (Números Especiales 1). Recuperado de https://www.unilim.fr/trahs/index.php?id=325.

Rico, L. (2010). En Tumaco, ni la palma crece ni la coca se marchita. La Silla Vacía, 13 de abril. Recuperado de http://lasillavacia.com/historia/9717

Sánchez, N. (2017). Nuestro territorio es un campo de batalla: Awás de Tumaco. El Espectador, 29 de octubre. 
https://www.elespectador.com/colombia2020/pais/nuestro-territorio-es-un-campo-debatalla-awas-de-tumaco-articulo-855954

Schultze-Kraft, M. (2016). Órdenes crimilegales: repensando el poder político del crimen organizado. Íconos. Revista de Ciencias Sociales, (55), pp. 25-44.

Segura, F., y Maldonado, A. (2009). Palma de aceite y desplazamiento forzoso en Colombia. Tesis de maestría en Economía, Universidad de los Andes, Bogotá.

Subra, P. (2016). Géopolitique locale. Territoires, acteurs, conflits. París: Armand Colin.

The Guardian (2018). Colombian army killed thousands more civilians than reported, study claims. The Guardian, 8 de mayo. Recuperado de https://www.theguardian.com/world/2018/may/08/colombia-false-positives-scandal-casualties-higherthought-study

UNODC (Oficina de las Naciones Unidas para la Droga y el Delito). (2019). Colombia. Monitoreo de territorios afectados por cultivos ilícitos 2018. Bogotá: UNODC. Recuperado de https:/www.unodc.org/documents/colombia/2019/Agosto/Informe_de_Monitoreo_de_Territorios_Afectador_por_Cultivos_Ilicitos_en_Colombia_2018_.pdf

Verdad Äbierta (2015). Barbacoas: un olvido, muchos conflictos. Verdad Abierta.com, 13 de mayo. Recuperado de https://verdadabierta.com/barbacoas-narino-un-olvido-muchosconflictos/

Zuleta, H. (2017). Coca, cocaína y narcotráfico. Documentos CEDE, (42). Recuperado de https:/economia.uniandes.edu.co/components/com_booklibrary/ebooks/dcede201742.pdf 